\title{
POBLACIÓN Y TAMAÑO MUNICIPAL: REFLEXIONES A PARTIR DEL CENSO DE 1991
}

\author{
POR \\ ARLINDA GARCÍA COLL \\ $\mathrm{Y}$ \\ DOLORES SÁNCHEZ AGUILERA
}

\begin{abstract}
Bajo una apariencia general de continuidad, el Censo de Población de 1991 deja entrever algunos rasgos que constituyen signos inequívocos de ruptura respecto a censos anteriores. Así, aunque la mayoría de las tablas -y lo que es todavía más importante, las categorías que emplean éstas para la clasificación de los datos- respetan los criterios formales utilizados en el Censo inmediatamente anterior (1981), lo cierto es que la difusión de la información relativa a la operación de 1991 incorpora cambios de fondo de índole diversa.

El Censo de 1991 es el primero en la historia española en el que se informatizan las características sociodemográficas recogidas a nivel individual de la totalidad de la población. El resultado final es un fichero completo que permite realizar cualquier explotación sobre el total de los censados y no sobre una muestra, como sucedía en operaciones anteriores. La confianza que ofrece trabajar con datos exhaustivos se traduce en una ampliación de la oferta de las tablas generadas a nivel municipal, escala tradicionalmente descuidada debido
\end{abstract}

Arlinda García Coll y Dolores Sánchez Aguilera. Universidad de Barcelona

Estudios Geográfico

Tomo LVIII, n. ${ }^{\circ} 229$, octubre-diciembre 1997 
a las limitaciones derivadas del manejo muestral. Desde el Censo de 1877, la escala municipal había sido relegada por las estadísticas españolas en favor de la presentación de datos agregados: partidos judiciales y ciudades de cierto tamaño demográfico primero, y agregaciones en razón del tamaño demográfico de la entidad más tarde. En cambio, para 1991 se dispone de un total de 20 tablas de diversas variables, todas ellas cruzadas por sexo, para cada uno de los municipios españoles. Esta información no se publica en papel sino en soporte magnético, en lo que se ha denominado el SAETA (Sistema de Almacenamiento Electrónico de Tabulaciones) ${ }^{1}$. SAETA presenta las mismas tabulaciones para todos los municipios, ignorando consideraciones como el número de habitantes o la condición de capital provincial que anteriormente determinaban un tratamiento especial de ciertas unidades.

Como contrapartida, desaparecen las tabulaciones que utilizaban como criterio territorial el tipo de hábitat y clasificaban la población según tres grandes categorías: rural, intermedia y urbana. Estos epígrafes eran definidos únicamente a partir del número de habitantes, con lo que eran más un recurso estructurador de la información que un instrumento diferenciador entre lo rural y lo urbano.

El conjunto de cambios señalados desencadena una serie de repercusiones que afectan directamente a la dimensión geográfica de las investigaciones. Por un lado, se dispone de mucha información municipalizada, lo que permite la comparación espacial de características como la estructura demográfica, la relación con la actividad o la composición social de la población con un detalle territorial imposible hasta la fecha. Esta riqueza tan sólo se ve empañada por la falta de una serie temporal que vaya más allá del número total de habitantes por municipio ${ }^{2}$, circunstancia que impide cualquier comparación

1 El Censo de Población de 1991 dedica a la escala municipal el volumen tercero de la difusión de datos. Este volumen contiene mucha menos información que SAETA, pues selecciona aquellos datos que juzgan como de mayor interés además de substituir algunas cifras brutas por indicadores, como por ejemplo, la proporción de mayores de 65 años, respetando la práctica propia de censos anteriores. Este hecho no es de extrañar, pues la publicación de SAETA daría pie a un enciclopédico número de volúmenes.

2 El Censo de 1981 ofrece información municipalizada de la población de derecho por sexos. Es cierto que aporta hasta seis tablas más (población por grandes grupos de edad, por estado civil, por nivel de instrucción, según relación con la actividad y según sector de ocupación y situación profesional para los ocupados) pero en estos casos sólo ofrece los porcentajes ya calculados sobre un total generalmente desconocido y nada se sabe del número de personas que representan. 
temporal con excepción del crecimiento de la población ${ }^{3}$. Por otro lado, cualquier análisis que pretenda abordar la población del conjunto nacional se enfrenta al dilema de trabajar con 52 unidades (provincias y Ceuta y Melilla) o con los 8.077 municipios.

En consecuencia, surgen una serie de retos metodológicos que no son precisamente de fácil solución, ya que muchos de ellos pueden considerarse todavía como verdaderas «asignaturas pendientes» de la Geografía. En primer lugar, y en relación con las escalas de análisis, cualquier investigación de cierta magnitud que quiera utilizar el SAETA debería delimitar previamente unas unidades de análisis que resulten de la suma de municipios y que se adapten al objeto de estudio, pues la interpretación de la realida ${ }_{\llcorner}$municipal sobrepasa la operatividad analítica cuando se trabaja cor el conjunto de España. En segundo lugar, sería preciso incidir en el desarrollo de estrategias metodológicas destinadas a abordar los comportamientos de aquellos municipios cuyo reducido volumen de población resta significación a los indicadores obtenidos o, al menos, obliga a matizar su interpretación.

En un plano muy distinto, cabe lamentar la desaparición de algunas explotaciones existentes anteriormente que ahora ven frustrado cualquier intento de actualización. Este es el caso del tratarniento especial que se realizaba para las capitales provinciales y para las grandes ciudades, donde determinadas variables llegaban incluso a desagregarse por distritos ${ }^{4}$. Igualmente, han desaparecido las tablas que presentaban los resultados intraprovinciales atendiendo a determinados umbrales demográficos, que consideraban población rural la que vive en entidades menores de 2.000 habitantes y urbana la que lo hace en aquellas mayores de 10.000 , siendo la restante denominada intermedia. Esta clasificación, que se remonta al Censo de 1950, ha sido muy utilizada en todo tipo de estudios y su utilidad es ampliamente reconocida en la mayoría de ellos. Cabe tener en cuen-

3 Cabe señalar que todas estas afirmaciones hacen referencia a la disponibilidad para el conjunto de España y, por tanto, podrían ser matizadas para cada una de las Autonomías que disponen de Instituto de Estadística o publicaciones propias.

${ }_{4}$ Desde mayo de 1997 se encuentra en el mercado un nuevo producto informático, el CD-ROM llamado CERCA+100. Éste proporciona datos sobre agricultura, edificios, locales y población para la totalidad de secciones censales y para unidades de nomenclátor con una población superior a 100 habitantes. Esta publicación cubre parte del déficit de información de gran detalle territorial. 
ta, además, que estas categorías son irreconstruibles a partir del SAETA, pues éste trabaja con municipios mientras que el criterio de agrupación anterior se fijaba en la entidad de población.

En este contexto de cambio, el presente trabajo pretende poner en relación la tradición del uso de escalas intermedias en el análisis geográfico de la población y el nuevo formato de presentación de la información del Censo de 1991.

\section{Reorganizando la información territorial:}

las escalas intermedias de análisis

Las soluciones a las que se recurre para hacer frente al dilema entre adoptar una óptica provincial o una municipal se pueden agrupar en tres estrategias fundamentales. En primer lugar, en aquellas Autonomías donde existe una división comarcal consolidada, como en el caso de Cataluña, las comarcas han sido utilizadas como una escala intermedia de análisis. Sin embargo, esta opción se encuentra limitada por el hecho de que no existe una división comarcal reconocida para toda España, a excepción de las comarcas agrarias, y de que otros ensayos de comarcalización, tales como las comarcas propuestas por el INE para la presentación de microdatos, no acaban de satisfacer las expectativas de los investigadores ${ }^{5}$. En otros casos, se ha optado por la delimitación de áreas ajustadas al tema de estudio o bien de tipo funcional. Estas áreas requieren unas nociones previas del objeto de estudio al igual que un excelente conocimiento del territorio, tareas que en muchas ocasiones significarían ya de por sí

5 Con motivo de la difusión de muestras de registros individualizados (del $2 \%$ ó $10 \%$ de la población), el INE garantiza el secreto estadístico anonimizando determinadas variables. Desde el punto de vista geográfico, esta operación significa la sustitución del identificador municipal por un código comarcal en los menores de 20.000 habitantes. Estas comarcas -expresamente definidas para cubrir dicha finalidad- resultan de la suma de municipios de una misma provincia, con la única condición de que formen un contínuo geográfico y de que todas ellas tengan en torno a 20.000 habitantes. Lógicamente, las comarcas resultantes acumulan todo tipo de deficiencias, entre las que cabe señalar su desigual concepción (en las provincias más pobladas, dos municipios forman ya una comarca, mientras que en las menos pobladas traspasar el umbral de los 20.000 habitantes significa la agrupación de una importantísima porción provincial) y, lo que es todavía más grave, la mezcla en una misma comarca de municipios de característiscas sociodemográficas totalmente contrastadas. 
una investigación propia. Finalmente, en otros casos, un recurso sencillo ha sido el uso de la agregación territorial según tamaño demográfico ${ }^{6}$. El tamaño demográfico ha sido un criterio habitual en investigaciones que proceden tanto de la propia Geografía como de otras disciplinas que requieren poner orden al territorio o dividirlo de acuerdo con algún factor objetivo. Su utilidad ha sido puesta en evidencia de forma clara con la obtención de resultados en los que el corte según tamaño poblacional aparece como elemento racionalizador. Son trabajos que inciden en las estructuras demográficas (Abellán et alii, 1989 y 1996; Sánchez Aguilera y García Coll, 1995), en la estructura sectorial de la ocupación (López Jiménez, 1991), así como aquéllos que abordan en el crecimiento de la población (Ferrer Regales, 1994) o el impacto de las migraciones (Camarero, 1993). A ellos cabe añadir, los estudios que se centran en un segmento de población y que toman el corte poblacional como elemento de referencia: población rural (Higueras y Faus, 1992; Vidal, 1989); intermedia (Serrano, 1986) o urbana (Precedo Ledo, 1986; Tobío, 1985; Vinuesa, 1996).

A pesar de todo, la propuesta basada en el uso de la agregación según tamaño demográfico despierta numerosos recelos $\mathrm{y}$ ha sido cuestionada fundamentalmente por dos motivos:

a) En primer lugar, debido a que los municipios españoles son fruto de unos procesos históricos diferenciales y ocultan formas diversas de asentamiento de la población en el territorio. Es por ello que bajo la común denominación administrativa de municipio coexisten realidades bien distintas. Ejemplo de esta circunstancia es Galicia, donde el municipio es una agrupación de entidades de menor rango, las parroquias, frente a algunas provincias andaluzas, donde existe una mayor correspondencia entre municipio y núcleo de población. Tampoco hay que olvidar su dimensión física, ya que la fragmentación municipal del norte español poco tiene que ver con la ma-

6 Una aportación que combina los criterios de tamaño demográfico y los funcionales es la clasificación municipal desarrollada en diversas publicaciones por Ferrer Regales y equipo. Dicha clasificación diferencia entre áreas metropolitanas -con un tratamiento específico para los municipios centrales- ciudades intermedias y cabeceras comarcales, retomando para su identificación los trabajos sobre comarcalización de Casas Torres (1973). 
yor extensión, en general, de los municipios meridionales, aspecto que condiciona el volumen de población residente en cada caso. Asimismo, la mayor incidencia del poblamiento disperso en algunas regiones españolas sesga parcialmente la información cuando se trabaja con entidades de población. Finalmente, cabe añadir la heterogeneidad de los criterios aplicados en las políticas de agregaciones y segregaciones municipales, que da lugar a trayectorias territoriales diferentes en la génesis de unidades administrativas. Este conjunto de limitaciones puede resolverse, al menos parcialmente, incorporando el mapa de los municipios españoles a cualquier discurso que utilice umbrales demográficos, es decir, teniendo siempre presente cuál es la porción de territorio de la que se está hablando.

b) En segundo lugar, seguramente como elemento más perjudicial, se encuentra la carga de significación que se suele atribuir a los conceptos de rural y urbano, que ha dado pie a numerosos trabajos cuyo objetivo es establecer diferencias (e incluso límites) entre lo rural y lo urbano ${ }^{7}$. La imposibilidad de definir dichos conceptos a partir de un criterio basado únicamente en el lugar de residencia de la población explica las reticencias a considerar rurales a aquéllos que residen en un municipio periurbano simplemente porque su población no supere los 2.000 habitantes, o a englobar en la misma categoría a los habitantes de una gran capital y a los de una agrociudad, por el hecho de que ambas poblaciones municipales cuenten con más de 10.000 habitantes. Este espinoso debate -no finalizado por su enorme complejidad- lleva a extremar las precauciones a la hora de emplear dichos conceptos. En esta situación, el INE ha retirado cualquier alusión al tipo de hábitat y cuando realiza alguna explotación en función del tamaño define las categorías en base al tamaño demográfico que representan.

Sin olvidar las limitaciones de las escalas intermedias que se han ido reseñando, cabe señalar el papel que desempeñan como alternativa a las divisiones administrativas básicas cuando se trata de ordenar grandes volúmenes de información municipalizada, como es el caso de los datos ofrecidos por el último Censo. Ahora bien, el objetivo primordial de este nivel de análisis debe centrarse en la misión de

7 Entre los intentos de delimitación, es de obligatoria referencia el artículo de $\mathrm{H}$. Capel: «La definición de lo urbano» en el que se revisan los distintos conceptos del hecho urbano. 
ofrecer imágenes globales de las situaciones, que sirvan para la contextualización de los fenómenos a estudiar.

Enlazando con esta perspectiva, este trabajo explora las posibilidades del uso de los tamaños demográficos de los municipios como elemento racionalizador de la multiplicidad de situaciones que suponen los resultados del Censo de 1991, correspondientes a los más de 8.000 municipios españoles. Al partir de datos municipales, es posible evitar algunos de los reduccionismos de la clasificación histórica: en primer lugar, se ha establecido una categorización por tamaños que supera la división tripartita de rural, intermedio y urbano y permite afinar en la diferenciación de comportamientos; en segundo lugar, la referenciación territorial concreta sobre el mapa posibilita una lectura geográfica de los resultados, sobre cualquier otra de transfondo conceptual más amplio. Por último, cabe indicar que una de las virtudes de esta clasificación es el hecho de que se pueden establecer relaciones entre volumen poblacional y trayectoria demográfica, lo que abre la posibilidad de trazar una historia común para los municipios de un determinado tamaño, superándose factores de diferenciación local que, lógicamente, inciden en los casos particulares.

\section{Población y tamaño demográfico municipal:} hacia la polarización de situaciones

La distribución actual de la población española muestra los efectos del proceso de urbanización experimentado por nuestro país. De este modo, no sólo hay que destacar la progresiva desaparición de municipios a lo largo del siglo xx debido al gradual despoblamiento (que justifica buena parte de las decisiones de agregaciones municipales), sino que los cambios más significativos se han producido en materia de la distribución de la población.

Así, de una situación inicial en 1900 donde las categorías pequeñas y medianas congregan la mayor parte de los municipios y de la población española, se pasa a un contexto marcado por un doble desequilibrio. En primer lugar, la distribución de los habitantes y la del territorio tienden a distanciarse, de forma que cada vez existe menor relación entre el porcentaje de municipios que representa cada categoría y la proporción de población que alberga. En segundo lugar, la serie muestra una clara tendencia hacia la polarización, es decir, ha-

$$
-599-
$$


cia una aumento de municipios más pequeños (menores de 500 habitantes) y la concentración de la población en los más habitados. El cuadro I muestra la distribución de los municipios y la población según tamaño demográfico en tres momentos representativos de su evolución a lo largo del siglo xx.

Cuadro I

MUNICIPIOS SEGÚN TAMAÑO DEMOGRÁFICO

\begin{tabular}{l|r|r|r|r|r|r}
\hline \multirow{2}{*}{$\begin{array}{c}\text { Tamaño del } \\
\text { municipio }\end{array}$} & \multicolumn{3}{|c|}{ Número de municipios } & \multicolumn{3}{c}{ \% de municipios } \\
\cline { 2 - 7 } & $\mathbf{1 9 0 0}$ & $\mathbf{1 9 5 0}$ & $\mathbf{1 9 9 1}$ & $\mathbf{1 9 0 0}$ & $\mathbf{1 9 5 0}$ & $\mathbf{1 9 9 1}$ \\
\hline$<100$ & 19 & 64 & 927 & 0,21 & 0,69 & 11,48 \\
$101-500$ & 3.176 & 2.975 & 2.882 & 34,27 & 32,29 & 35,68 \\
$501-2.000$ & 4.020 & 3.701 & 2.176 & 43,38 & 40,17 & 26,94 \\
$2.001-5.000$ & 1.378 & 1.485 & 1.018 & 14,87 & 16,12 & 12,60 \\
$5.001-10.000$ & 454 & 584 & 491 & 4,90 & 6,34 & 6,08 \\
$10.001-20.000$ & 150 & 256 & 298 & 1,62 & 2,78 & 3,69 \\
$20.001-50.000$ & 52 & 95 & 172 & 0,56 & 1,03 & 2,13 \\
$50.001-100.000$ & 12 & 30 & 57 & 0,13 & 0,33 & 0,71 \\
$100.001-500.000$ & 4 & 21 & 50 & 0,04 & 0,23 & 0,62 \\
$>500.001$ & 2 & 3 & 6 & 0,02 & 0,03 & 0,07 \\
\hline Total & 9.267 & 9.214 & 8.077 & 100,00 & 100,00 & 100,00 \\
\hline
\end{tabular}

CuAdro I Bis

POBLACIÓN SEGÚN TAMAÑO DEMOGRÁFICO

\begin{tabular}{l|r|r|r|r|r|r}
\hline \multirow{2}{*}{$\begin{array}{c}\text { Tamaño del } \\
\text { municipio }\end{array}$} & \multicolumn{3}{|c|}{ Número de habitantes } & \multicolumn{3}{c}{ \% de población } \\
\cline { 2 - 7 } & $\mathbf{1 9 0 0}$ & $\mathbf{1 9 5 0}$ & $\mathbf{1 9 9 1}$ & $\mathbf{1 9 0 0}$ & $\mathbf{1 9 5 0}$ & $\mathbf{1 9 9 1}$ \\
\hline$<100$ & 1.606 & 5.357 & 56.316 & 0,01 & 0,02 & 0,14 \\
$101-500$ & 1.037 .486 & 922.847 & 738.293 & 5,57 & 3,28 & 1,87 \\
$501-2.000$ & 4.086 .241 & 3.779 .508 & 2.284 .470 & 21,95 & 13,44 & 5,79 \\
$2.001-5.000$ & 4.343 .197 & 4.712 .429 & 3.187 .638 & 23,33 & 16,76 & 8,08 \\
$5.001-10.000$ & 3.152 .655 & 4.054 .930 & 3.394 .233 & 16,93 & 14,42 & 8,61 \\
$10.001-20.000$ & 2.014 .542 & 3.360 .742 & 4.102 .341 & 10,82 & 11,95 & 10,40 \\
$20.001-50.000$ & 1.447 .832 & 2.657 .505 & 4.979 .662 & 7,78 & 9,45 & 12,63 \\
$50.001-100.000$ & 856.723 & 1.884 .194 & 3.773 .817 & 4,60 & 6,70 & 9,57 \\
$100.001-500.000$ & 603.513 & 3.332 .672 & 9.512 .029 & 3,24 & 11,85 & 24,12 \\
$>500.001$ & 1.072 .835 & 3.407 .689 & 7.405 .143 & 5,76 & 12,12 & 18,78 \\
\hline Total & 18.616 .630 & 28.117 .873 & 39.433 .942 & 100,00 & 100,00 & 100,00 \\
\hline
\end{tabular}

Fuente: Elaboración propia a partir de INE, Anuario Estadistico de España, 1994.

$$
-600-
$$


Tomando 1900 como punto de partida, los resultados para 1950 evidencian los efectos de la primera fase de urbanización, si bien las modificaciones más notables se producen en la segunda mitad del siglo xx, de las que son testimonio los datos relativos a 1991. En la primera fase de urbanización, se produce un primer trasvase de población desde los municipios pequeños hacia los de mayor tamaño, especialmente capitales de provincia $\mathrm{y}$, sobre todo, hacia las grandes ciudades que son los máximos focos de atracción. Ello explica el aumento de la población que vive en localidades de cierto tamaño en detrimento de los que lo hacen en el mundo rural. Esta tendencia se ve acentuada durante la segunda fase de urbanización, pues es en este momento cuando el éxodo rural alcanza sus más altas cotas, generando los cambios más drásticos. El abandono de los municipios pequeños (emigración) y su falta de potencial revitalizador (crecimiento natural negativo) explica el descenso general de la población que reside en zonas rurales. No obstante, se constata un rapidísimo incremento de los municipios menores de 100 habitantes, al convertirse en el estadio que acoge a los espacios que anteriormente ocupaban categorías superiores y que ahora están en regresión. Aun así, estas cifras enmascaran el aumento real de esta categoría, que se difumina como consecuencia de las continuas agregaciones de micromunipios. En esta segunda fase de urbanización, las grandes ciudades no acaparan ya todo el protagonismo sino que lo comparten con otros municipios de su entorno. Así, las migraciones hacia las ciudades industriales no afectan exclusivamente a las núcleos centrales, sino que su incidencia se extiende por sus municipios limítrofes (áreas metropolitanas) que acogen a los inmigrantes que las grandes urbes no pueden absorber. Las capitales de provincia o los centros comarcales dinámicos -que lideran los destinos en las migraciones de corta distancia o intraprovinciales- junto con aquellos ámbitos intermedios que tienen una actividad industrial predominante, tienen también un papel relevante a la hora de explicar el papel asumido por los niveles intermedios (Serrano, 1986).

Los procesos descritos hasta el momento finalizan durante la segunda mitad de los 70 y se inicia una nueva fase calificada por algunos autores como post-industrial (Precedo Ledo, 1986). En esta etapa ya no son las grandes ciudades las que crecen de forma más intensa, sino que llegan a experimentar un estancamiento poblacional e inclu- 
so la pérdida continuada de habitantes. En cambio, las áreas urbanas de menos de 500.000 habitantes toman el relevo y se convierten en determinantes en la estructuración del territorio, pues crecen en número y, sobre todo, en potencial demográfico. Por su parte, el número de municipios de menor tamaño no deja de incrementarse, así como su volumen de habitantes. La modificación de comportamientos en el período más reciente se abordará de forma más extensa más adelante, cuando se analiza el crecimiento demográfico experimentado durante el período 1981-91.

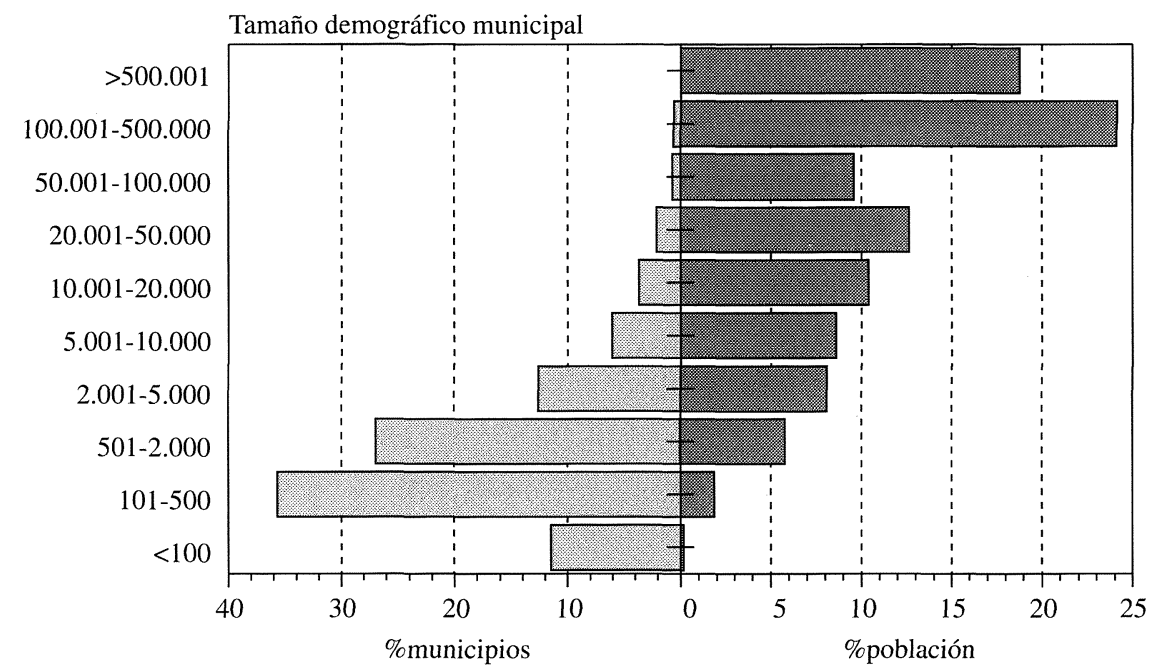

Fuente: Elaboración propia a partir de INE, Saeta, 1991.

FIGURA 1.-Estructura poblacional según tamaño demográfico.

Como resultado final de todo este conjunto de procesos, en 1991, un $74 \%$ de los municipios españoles tiene menos de 2.000 habitantes y un $47 \%$ menos de 500 . Este ámbito, habitualmente identificado con el nombre de rural, alberga un 7,8\% de la población española y, a pesar del pequeño porcentaje que representa, alcanza un volumen demográfico de 3.079.079 personas. Esta categoría forma un amplio continuum geográfico que se localiza, básicamente, en la mitad septentrional de la Península. La dicotomía norte-sur se ve truncada por algunos casos excepcionales: en primer lugar, Galicia, Asturias y la 
franja litoral cantábrica, adquieren rasgos específicos debido a que la división municipal no coincide con la estructura de poblamiento nuclear que se da en otras regiones españolas; en segundo lugar, se dibujan diversos ejes como el litoral mediterráneo o el valle del Ebro, que han desarrollado una dinámica más activa de crecimiento en la reciente historia demográfica española y por ello presentan unidades más pobladas. Así pues, los denominados municipios rurales son un conjunto que se extiende por la Meseta norte, el Sistema Ibérico y los Pirineos y por algunas zonas montañosas de la mitad meridional: Sierra de Aitana en Alicante, Sierra de Gata y Sierra de Gredos, Montes de Toledo, Sierra de Alcaraz, Serranía de Ronda, Sierra Nevada y Filabres, Sierra de Aracena, entre otros. Por otro lado, el mapa I muestra cómo en este continuo geográfico se registra una gradación de tamaños, de manera que los municipios con menos habitantes se sitúan progresivamente en las zonas más periféricas respecto a categorías superiores.

Los municipios comprendidos entre 2.001 y 10.000 habitantes (mapa II) forman un grupo que, desde el punto de vista territorial, muestra una coherencia menor que las categorías anteriores. Fundamentalmente se encuentran localizados en la mitad meridional de la Península, donde la extensión municipal media es superior, y en ambos archipiélagos, así como en Galicia y franja costera cantábrica, por los motivos ya señalados. Además, han experimentado una variación menor que el grupo anterior: la disminución del número de municipios entre 2.001 y 5.000 habitantes se compensa con un leve aumento de aquéllos cuya población se sitúa entre 5.001 y 10.000 habitantes. Estas pequeñas diferencias en cuanto a su número se incrementan si se tienen en cuenta los cambios respecto a la población que representan: en 1900 , sumaban un $40 \%$ de la población total que se ha visto reducido a un $16,69 \%$ según las últimas cifras.

Por último, los municipios urbanos (mapa III y IV) son actualmente un conglomerado diverso que responde a dinámicas heterogéneas y que se puede subdividir en dos grupos. El primero, formado por aquellos ámbitos de hasta 50.000 habitantes, está integrado por municipios del litoral mediterráneo y fachada atlántica andaluza, por un conjunto enclavado en el valle del Guadalquivir, por municipios de gran superficie en Murcia y la meseta sur y algunos ejemplos en el Principado de Asturias y Galicia. Estas categorías han registrado una 


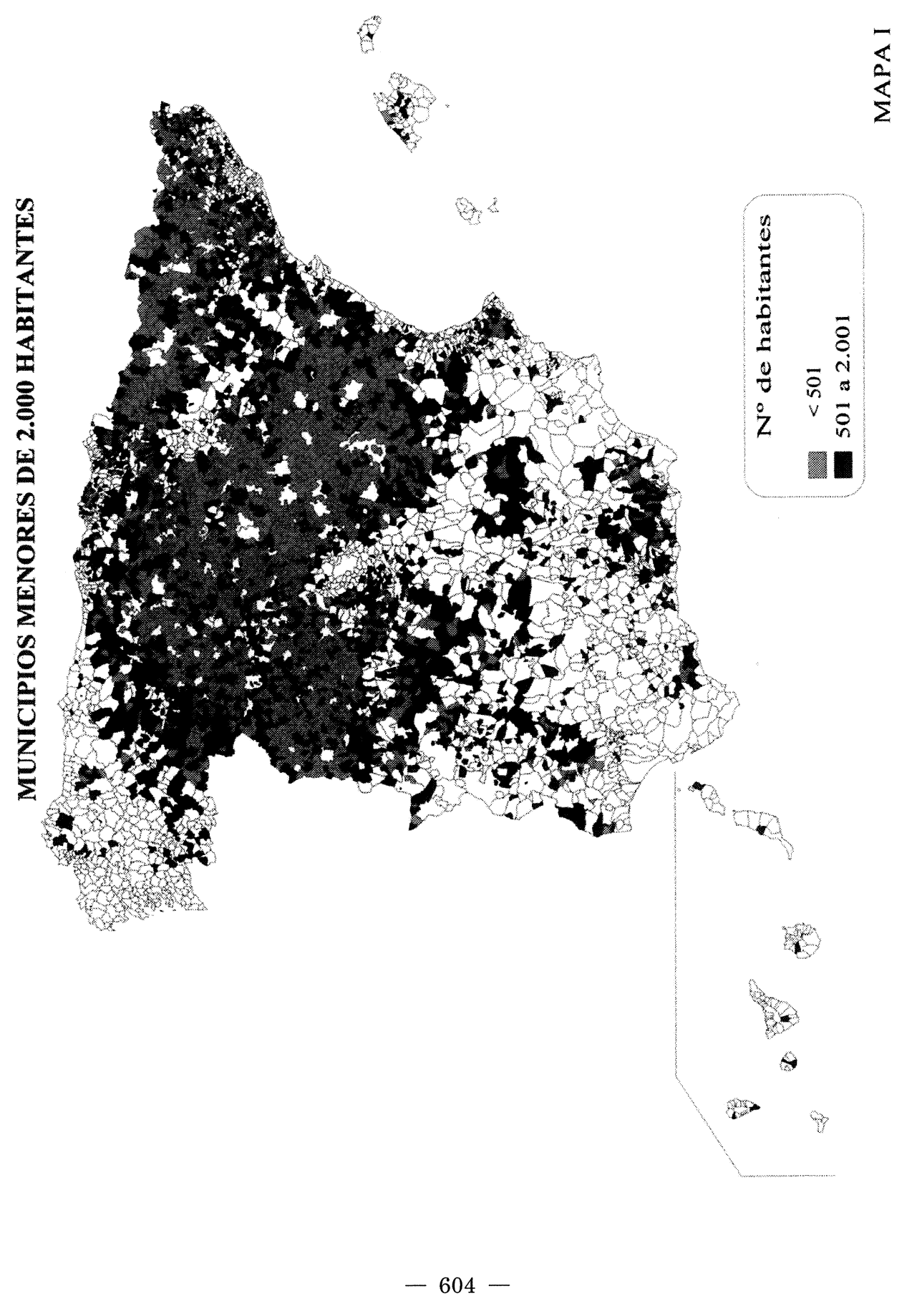

(c) Consejo Superior de Investigaciones Científicas 


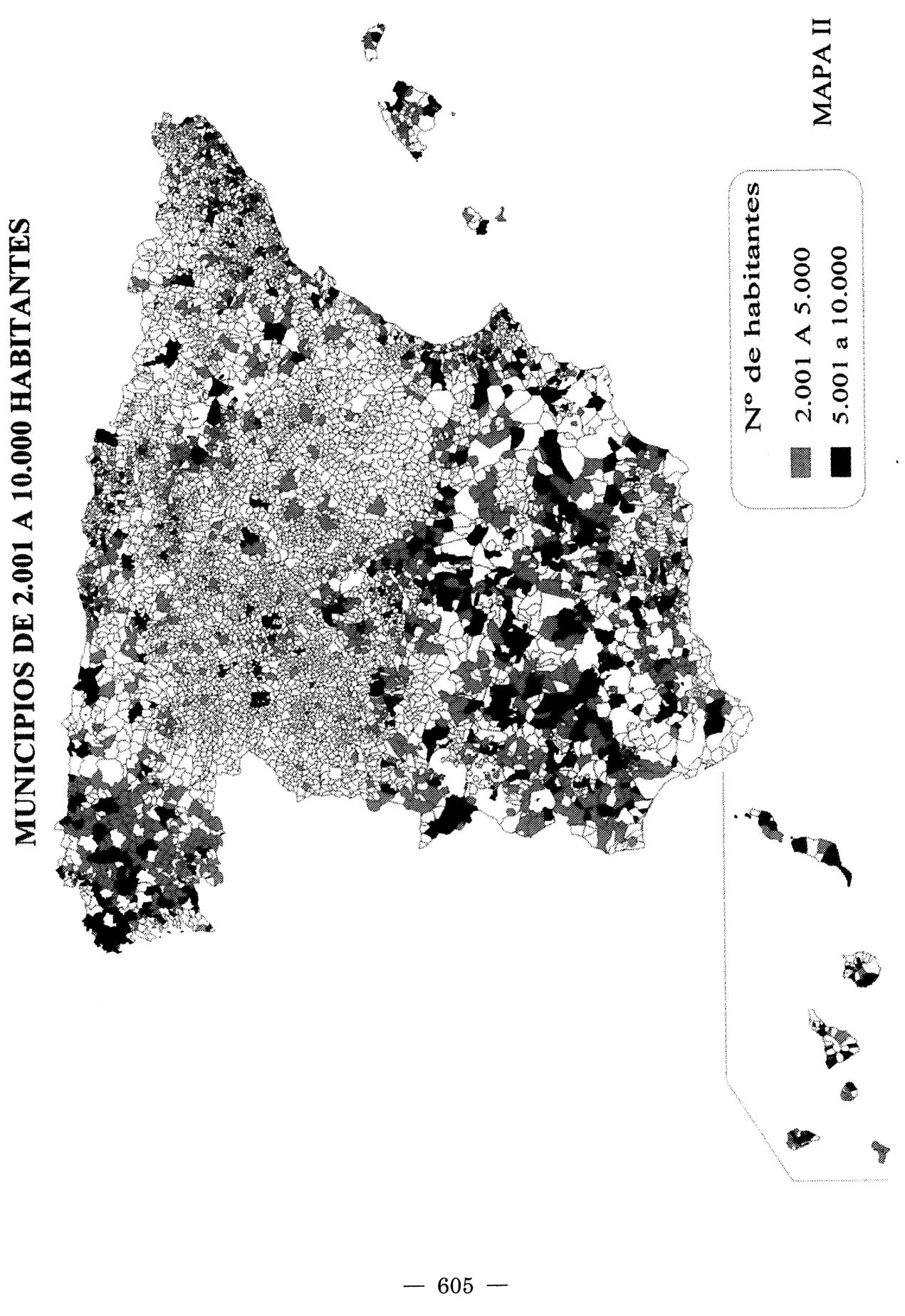

(c) Consejo Superior de Investigaciones Científicas 


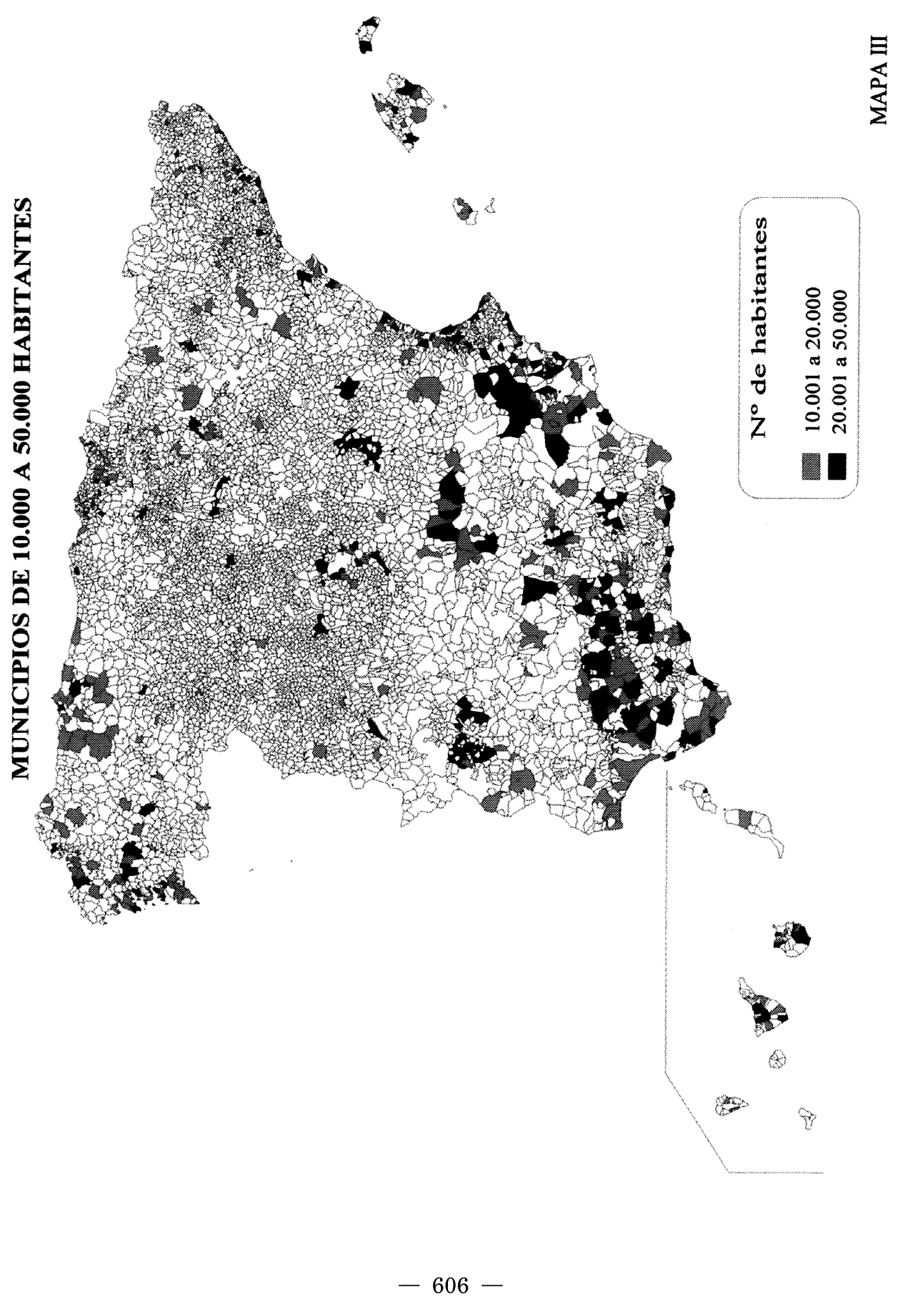




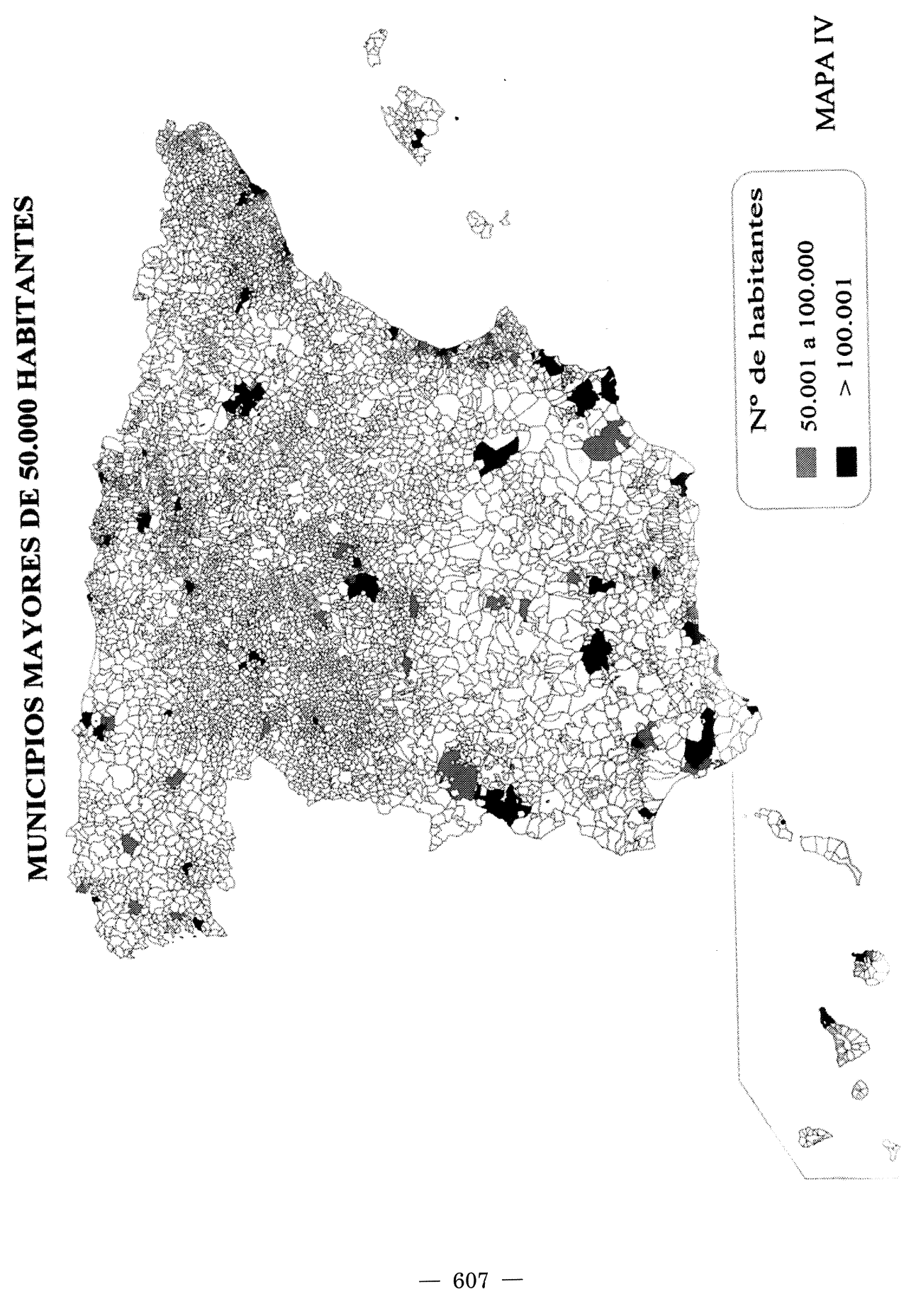

(c) Consejo Superior de Investigaciones Científicas 
moderada expansión desde comienzos de siglo, tanto en número (de representar al $2,18 \%$ de los municipios al $5,82 \%$ en 1991 ) como en volumen demográfico $(18,60 \%$ y $23,03 \%$ de la población, respectivamente). El segundo grupo, correspondiente a los municipios urbanos de mayor tamaño (más de 50.000 habitantes), está constituido por un número reducido de casos, generalmente capitales provinciales y ciudades del entorno metropolitano, y son las categorías que más peso demográfico han ganado en el transcurso de este siglo, en especial las ciudades que superan los 100.000 habitantes que albergan actualmente un $42,90 \%$ de la población aunque sólo son un $0,69 \%$ de los municipios. Por su parte, en las seis ciudades más pobladas del país residen prácticamente el $20 \%$ de los españoles, aunque la tendencia de éstas es la pérdida de población, tal y como se comprobará en el análisis del crecimiento reciente por tamaños.

Nuevas relaciones entre población y tamaño demográfico municipal: los resultados de 1991

La revisión del comportamiento de los municipios agrupados según tamaño demográfico ha permitido establecer trayectorias comunes para los componentes de las diferentes categorías a lo largo de su historia demográfica en el siglo xx.

En su etapa más reciente, definida por el último período intercensal, es decir, 1981-91, la población conoce una serie de cambios que hacen cuestionar el mantenimiento de tendencias compartidas de las categorías municipales, tal y como sucedía en el pasado. La redefinición reciente de las relaciones entre población y tamaño demográfico se analiza mediante el análisis de tres indicadores: crecimiento de población en el período 1981-91, la naturaleza de la población y, finalmente, la estructura demográfica.

a) Crecimiento de la población: declive de las grandes ciudades y auge de las ciudades medias

Frente a otros indicadores mucho más estables, el crecimiento de la población actúa como testigo inmediato de la situación coyuntural, 
en este caso del decenio 1981-91. Con el objetivo de calcular tasas de crecimiento anual acumulativo ( $r \%$ ) comparables, la población por tamaños se ha homogeneizado tomando como criterio la categoría a que pertenecían en 1991. Se han corregido, por tanto, las alteraciones fruto de agregaciones o segregaciones ocurridas durante dicho decenio a fin de poder trazar las trayectorias de los mismos conjuntos poblacionales.

Globalmente, la población española crece durante los últimos diez años a un ritmo lento, con una tasa de 0,31\% anual (Cuadro II). Sin embargo, el análisis por tamaños descubre una realidad oculta por el promedio general. Así, el resultado pone en evidencia que las tasas más intensas tienen signo negativo y son, todavía, las experimentadas por los municipios de menor tamaño.

Cuadro II

CRECIMIENTO RECIENTE DE LA POBLACIÓN (1981-1991)

\begin{tabular}{l|r|r|r|r}
\hline \multirow{2}{*}{$\begin{array}{c}\text { Tamaño del } \\
\text { municipio }\end{array}$} & \multicolumn{2}{|c|}{ Población total } & \multicolumn{2}{c}{ Crecimiento 1981-91 } \\
\cline { 2 - 5 } & $\mathbf{1 9 8 1}$ & $\mathbf{1 9 9 1}$ & \multicolumn{1}{c}{ Absoluto } & \multicolumn{1}{c}{$\mathbf{~ \% ~}$} \\
\hline$<100$ & 61.817 & 49.195 & -12.622 & $\mathbf{- 2 , 2 6}$ \\
$101-500$ & 893.122 & 757.377 & -135.745 & $-\mathbf{1 , 6 4}$ \\
$501-2.000$ & 2.499 .680 & 2.308 .435 & -191.245 & $\mathbf{- 0 , 7 9}$ \\
$2.001-5.000$ & 3.181 .201 & 3.131 .825 & -49.376 & $\mathbf{- 0 , 1 6}$ \\
$5.001-10.000$ & 3.327 .833 & 3.484 .076 & 156.243 & $\mathbf{0 , 4 6}$ \\
$10.001-20.000$ & 3.860 .427 & 4.158 .075 & 297.648 & $\mathbf{0 , 7 5}$ \\
$20.001-50.000$ & 4.482 .102 & 5.011 .617 & 529.515 & $\mathbf{1 , 1 2}$ \\
$50.001-100.000$ & 3.304 .258 & 3.601 .953 & 297.695 & $\mathbf{0 , 8 7}$ \\
$100.001-500.000$ & 8.725 .014 & 9.163 .242 & 438.228 & $\mathbf{0 , 4 9}$ \\
$>500.001$ & 7.357 .712 & 7.206 .473 & -151.239 & $\mathbf{- 0 , 2 1}$ \\
\hline Total & 37.693 .166 & 38.872 .268 & 1.179 .102 & $\mathbf{0 , 3 1}$ \\
\hline
\end{tabular}

Fuente: Elaboración propia a partir de INE, SAETA municipal, 1991.

De hecho, los municipios menores de 5.000 habitantes presentan tasas negativas para el período 1981-91, de forma que cuanto menor es la categoría, más intenso es su ritmo de decrecimiento. Los motivos que explican esta conducta son los procesos en los que se en-

$$
-609-
$$


cuentran inmersos, que suelen mostrar rasgos doblemente regresivos. Por un lado, se observa en muchos casos un crecimiento natural de su población de signo negativo, pues la pérdida de efectivos en edad joven durante el éxodo rural mermó de forma importante su capacidad reproductiva, mientras que el envejecimiento actual de su estructura explica la tendencia al aumento de las tasas brutas de mortalidad. Igualmente, los saldos migratorios mantienen, en general, un carácter expulsor, ya que una parte importante de la población rural joven sigue protagonizando desplazamientos de distancia variable en cuanto necesita ampliar sus estudios o mejorar sus oportunidades laborales. Este esquema se reproduce en la mayoría de municipios de menor tamaño, acentuándose estas condiciones descritas en los municipios más pequeños, ya que estos padecen también de manera más determinante las desigualdades que se derivan de la falta de servicios y equipamientos, o de expectativas formativas y laborales. Algunos municipios rurales se benefician de movimientos de retorno o de iniciativas dinámicas locales (como turismo rural, una agricultura competitiva o una especialización residencial, ya sea en primera o segunda residencia) y, en algunos casos, logran incluso reconducir la inercia de un pasado regresivo. El impacto de este tipo de fenómenos necesita de una amplia gama de matices, pues a pesar del denominado «renacimiento de lo rural» (Camarero, 1993), lo cierto es que un $84 \%$ de los municipios menores de 2.000 habitantes reducen su número de habitantes durante el último decenio intercensal.

Junto a los municipios más pequeños, sorprende encontrar a las ciudades que superan los 500.000 habitantes entre las áreas con tasas negativas. De hecho, el signo de este grupo viene causado por las cuantiosas pérdidas de población experimentadas por Madrid y Barcelona. El principal factor explicativo se halla en la salida de población debido a procesos de relocalización residencial, en parte por las migraciones de retorno (regreso de antiguos inmigrantes a su lugar de origen) pero sobre todo ligado al proceso de suburbanización hacia municipios cercanos. Estas ciudades, que fueron las grandes receptoras de población durante la etapa del éxodo rural, adquieren ahora saldos migratorios expulsores, con un ritmo de llegadas que no logra compensar el volumen de los flujos de salida. Se añade, además, el efecto del envejecimiento demográfico causado por la confluencia de factores varios tales como la llegada a edades avanzadas

$$
-610-
$$


del gran colectivo de inmigrantes llegados durante las décadas de los 50-60, la caída de la fecundidad y la emigración de adultos-jóvenes. Esta acumulación de factores causa un crecimiento natural negativo $\mathrm{y}$, en definitiva, contribuye activamente a la pérdida de población.

Finalmente, la franja correspondiente a los municipios que se sitúan entre los 5.000 y 500.000 habitantes son las áreas que experimentan un aumento del número de habitantes. No es casual que las tasas de crecimiento más elevadas se registren en las ciudades medias de la geografía española, es decir, entre 10.000 y 100.000 habitantes. Estas ciudades presentan componentes de dinamismo demográfico. Por un lado, con estructuras menos envejecidas, estas poblaciones acostumbran a disponer de un crecimiento natural de carácter positivo. Además, se han convertido, en algunos casos, en localizaciones alternativas -especialmente a nivel residencial-a las grandes ciudades altamente saturadas, por lo que actualmente reciben flujos de población procedentes de las urbes más densas. Estas ciudades medias también toman el relevo en las iniciativas dinamizadoras de tipo económico: centros industriales de creación reciente, mejor comunicados y con mayor disponibilidad de suelo a buen precio (Méndez, 1993), espacios de atractivo turístico y centros polarizadores de áreas de actividades agrícolas de altos rendimientos. La emergencia de estos espacios supone un desplazamiento de los polos de crecimiento de población respecto a los tradicionales, aunque, en la mayoría de los casos, no determina un alejamiento de los mismos, sino más bien una expansión territorial de su influencia.

\section{b) Naturaleza de la población: la huella del éxodo rural}

El análisis de la naturaleza de la población se aborda a partir de la proporción de personas nacidas en una provincia distinta a la que se encuentra residiendo en 1991. El motivo de elegir la variación provincial en lugar de la municipal se basa en que todavía siguen recogiéndose como falsas migraciones los nacimientos que se producen en un municipio distinto al de residencia. Al utilizar como criterio el cambio provincial, es inevitable la sobrevaloración del 
comportamiento en los municipios localizados en las fronteras provinciales, si bien al organizar la información según tamaño municipal, este efecto queda diluido y no interfiere en el comportamiento general de la serie (Cuadro III).

Este sencillo indicador permite valorar el impacto migratorio experimentado por cada una de las áreas, pues estima el peso de los llegados desde otras provincias sobre el total de residentes en 1991. De este modo, si el crecimiento de población en el último decenio funcionaba como exponente de las tendencias más recientes, la naturaleza de la población se convierte en un verdadero reflejo de la historia demográfica de la generaciones españolas vivas en 1991 . Y es que el impacto del éxodo rural ha sido decisivo en la configuración actual de la población, mientras que los comportamientos de la etapa post-industrial acusan su todavía reciente aparición. Igualmente, uno de los aspectos destacables dentro de las pautas más novedosas es el impulso adquirido por los movimientos intraprovinciales, que, evidentemente, no son recogidos por el presente indicador, que se centra en el cambio provincial.

La naturaleza de la población pone en evidencia una relación di-

Cuadro III

NATURALEZA DE LA POBLACIÓN, 1991

\begin{tabular}{l|r|r|r}
\hline \multirow{2}{*}{$\begin{array}{c}\text { Tamaño del } \\
\text { municipio }\end{array}$} & \multirow{2}{*}{$\begin{array}{c}\text { Población } \\
\mathbf{1 9 9 1}\end{array}$} & \multicolumn{2}{c}{ Nacidos en otra provincia } \\
\cline { 3 - 4 } & & Núm. & \multicolumn{1}{c}{$\%$} \\
\hline 100 & 49.195 & 4.491 & $\mathbf{9 , 1 3}$ \\
$101-500$ & 757.377 & 78.451 & $\mathbf{1 0 , 3 6}$ \\
$501-2.000$ & 2.308 .435 & 282.890 & $\mathbf{1 2 , 2 5}$ \\
$2.001-5.000$ & 3.131 .825 & 438.460 & $\mathbf{1 4 , 0 0}$ \\
$5.001-10.000$ & 3.484 .076 & 576.411 & $\mathbf{1 6 , 5 4}$ \\
$10.001-20.000$ & 4.158 .075 & 788.446 & $\mathbf{1 8 , 9 6}$ \\
$20.001-50.000$ & 5.011 .617 & 1.223 .471 & $\mathbf{2 4 , 4 1}$ \\
$50.001-100.000$ & 3.601 .953 & 972.291 & $\mathbf{2 6 , 9 9}$ \\
$100.001-500.000$ & 9.163 .242 & 2.578 .626 & $\mathbf{2 8 , 1 4}$ \\
$>500.001$ & 7.206 .473 & 2.603 .511 & $\mathbf{3 6 , 1 3}$ \\
\hline Total & 38.872 .268 & 9.547 .048 & $\mathbf{2 4 , 5 6}$ \\
\hline
\end{tabular}

Fuente: Elaboración propia a partir de INE, SAETA municipal, 1991. 
recta entre tamaño municipal y proporción de personas nacidas en otra provincia, es decir, cuanto mayor es el número de habitantes, mayor es la proporción de foráneos. Cabe señalar que la virtud de tomar el cambio provincial como punto de referencia recaba en que valora la movilidad de media y larga distancia, que es la que debe vencer una mayor oposición para realizarse. Los resultados obtenidos son, en consecuencia, muestra del poder de atracción de cada uno de los espacios considerados.

Destacan, por los elevados índices de aloctonía conseguidos, las grandes ciudades y sus áreas de influencia, centros industriales tradicionalmente muy inmigratorios. Un fenómeno similar -aunque de menor intensidad- afecta a las ciudades medias, mientras que los municipios de menor tamaño son los que manifiestan una capacidad de atracción menor (en torno a un modesto $10 \%$ ), ya que también su atractivo es inferior. En este sentido, la jerarquía urbana es el elemento clave para comprender los mecanismos de funcionamiento de las migraciones en las etapas pasadas, es decir, durante el éxodo rural, cuyos últimos cambios tan sólo son por el momento sensibles en aspectos coyunturales pero no todavía a niveles estructurales.

El seguimiento de la serie de la proporción de foráneos apunta, en su gradual aumento, dos claros puntos de inflexión. Si en los primeros estadios la progresión entre los datos se aproxima, el primer cambio drástico se produce en la categoría de los 20.000 habitantes, no sólo por ser el primero en que se supera el $20 \%$ de nacidos en otra provincia, sino porque se distancia de forma acentuada de las categorías inmediatamente anteriores. Es, por tanto, este tamaño el que establece los límites entre las áreas muy inmigratorias respecto al resto, porque es también este tamaño el que determina la existencia de gran número de servicios en el marco de la red urbana. Es por esta razón que algunos autores como Rodríguez Osuna (1983) establecen los límites de categoría urbana precisamente en este umbral. Sin embargo, las máximas diferencias se encuentran en las ciudades mayores de 500.000 habitantes, que con más de una tercera parte de su población nacida en otra provincia han sido las verdaderas vertebradoras de las migraciones interprovinciales españolas a lo largo del siglo xx. 
c) Las estructuras de población: envejecimiento urbano versus envejecimiento rural

Las estructuras demográficas muestran la composición por sexo y edad de la población de cada una de las categorías establecidas. En ellas es posible identificar las huellas dejadas por la dinámica de la población en las generaciones que se hallan representadas.

En el caso de la población española en 1991, las pirámides por tamaños comparten trazos comunes, tales como la desnatalidad de la guerra o la reciente caída de la fecundidad. Sin embargo, esbozan una composición modificada por la incidencia de las migraciones -especialmente por el papel desempeñado durante la etapa del éxodo rural- y por la precocidad e intensidad del descenso de la natalidad. La combinación de estos fenómenos en sus desiguales expresiones ofrece una gama de situaciones en el Censo de 1991 que son recogidas por sus correspondientes pirámides (figura 2).

Las pirámides españolas según tamaños presentan rasgos de madurez en todas sus categorías. No obstante, las discontinuidades entre las que responden a los menores de 2.000 habitantes y las restantes son apreciables a primera vista: las estructuras del mundo rural se caracterizan por un sobreenvejecimiento que se acentúa a medida que se reduce el tamaño considerado. De esta manera, la cúspide tiende a ganar protagonismo en el caso de los menores de 500 habitantes que, en su aspecto general, recuerda más a un perfil invertido que a una pirámide en sí. Los sucesivos procesos de emigración que han padecido los municipios de menor tamaño se dejan sentir en las edades centrales, donde la falta de efectivos es extrema, especialmente en lo que se refiere al sexo femenino. La emigración de adultos tiene su inmediato reflejo en la base, pues resta potencial reproductivo y hace más intensos los efectos del generalizado descenso de la fecundidad.

La pirámide de los municipios comprendidos entre 2.001 y 5.000 habitantes marca la transición hacia los tramos intermedios. En esta estructura se aprecia el efecto de la erosión de las edades centrales a causa de la emigración, que repercute ligeramente en un mayor envejecimiento, aunque apenas incide en la base de la misma.

Por su lado, las estructuras de los municipios entre $5.001 \mathrm{y}$ 20.000 habitantes son las que se ajustan mejor a la situación media 


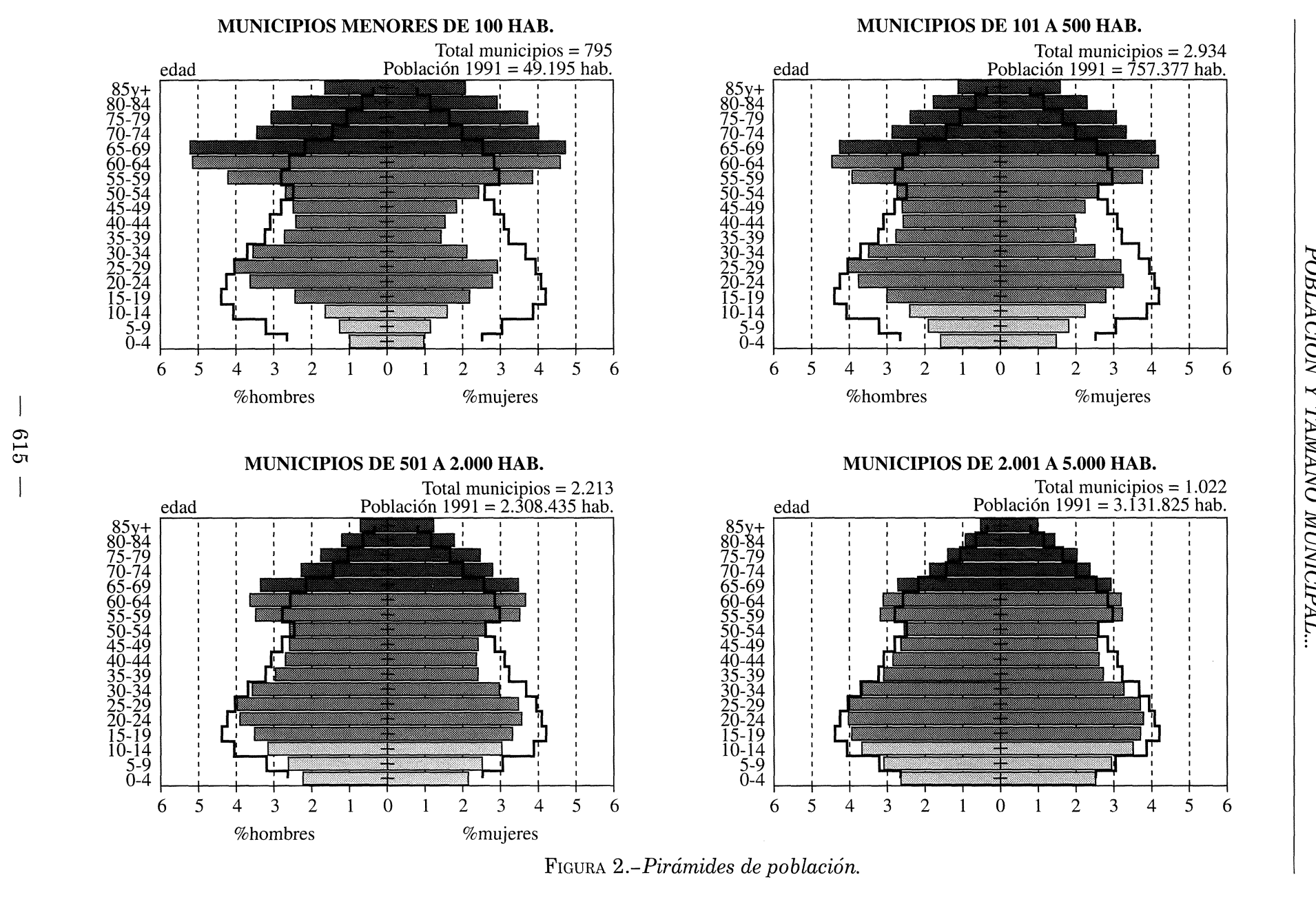

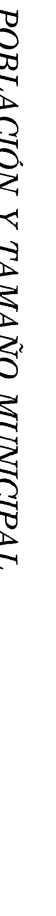



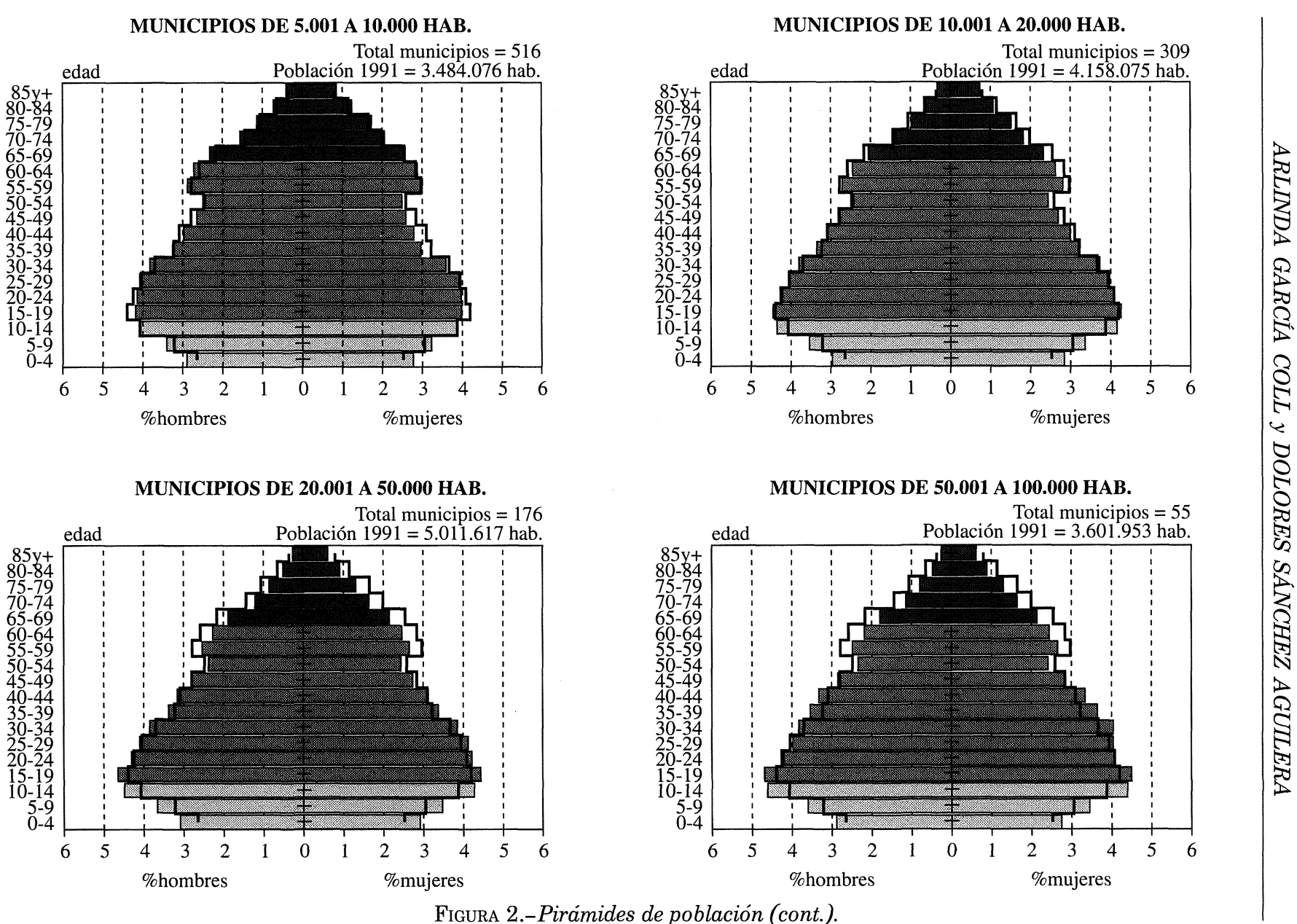

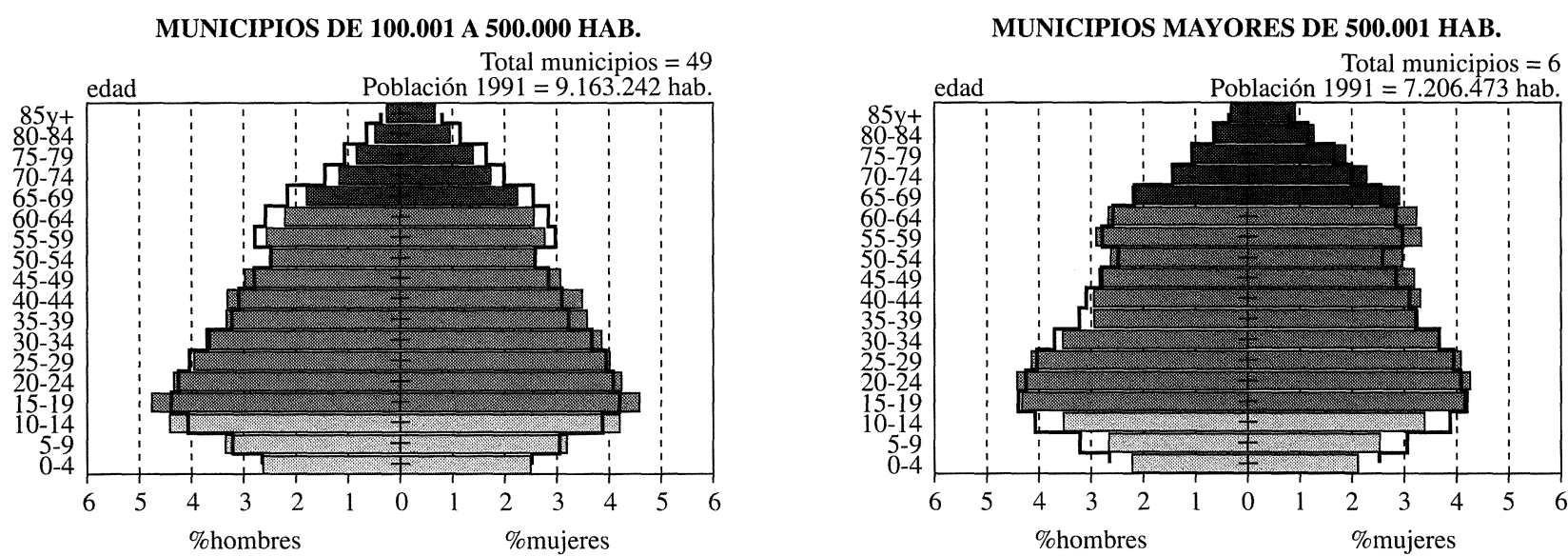
española, mostrando una elevada coincidencia respecto al conjunto nacional.

Las estructuras más rejuvenecidas se identifican en los tamaños comprendidos entre 20.000 y 500.000 habitantes. Estas ciudades han experimentado, y siguen en muchos casos experimentando, la inmigración de población adulta-joven que refuerza los efectivos concentrados en las edades centrales. De la misma manera, conocen un retroceso de la natalidad más tardío y menos intenso, en parte favorecidas por el carácter general de sus estructuras.

Por último, de nuevo son las grandes ciudades las que se desmarcan de la secuencia establecida por las categorías precedentes. Una caída de la fecundidad precoz y drástica, la erosión de las edades centrales por los procesos de suburbanización y el sobreenvejecimiento (causado por las migraciones de adultos durante la etapa del éxodo rural que ahora llegan a la edad de jubilación) son los aspectos que hacen diferir la estructura resultante de las anteriores.

Una forma de sintetizar todo el conjunto de incidencias descritas es el uso de indicadores de estructura (Cuadro IV). Estos indicadores

Cuadro IV

INDICADORES DE ESTRUCTURA DEMOGRÁFICA, 1991

\begin{tabular}{l|c|c|c|c|c|c}
\hline \multirow{2}{*}{$\begin{array}{c}\text { Tamaño del } \\
\text { municipio }\end{array}$} & \multicolumn{2}{|c|}{ Porcentaje } & \multicolumn{4}{c}{ Indicadores } \\
\cline { 2 - 7 } & Jóvenes & Viejos & IV & ID & IDV & MASC. \\
\hline \multirow{2}{*}{100} & 7,61 & 33,35 & 438 & 69 & 56 & 113 \\
$101-500$ & 11,43 & 26,79 & 234 & 62 & 43 & 106 \\
$501-2.000$ & 15,71 & 21,06 & 134 & 58 & 33 & 102 \\
$2.001-5.000$ & 18,38 & 17,20 & 94 & 55 & 27 & 100 \\
$5.001-10.000$ & 20,20 & 14,57 & 72 & 53 & 22 & 99 \\
$10.001-20.000$ & 21,21 & 12,79 & 60 & 52 & 19 & 98 \\
$20.001-50.000$ & 21,89 & 11,32 & 52 & 50 & 17 & 98 \\
$50.001-100.000$ & 21,67 & 10,99 & 51 & 49 & 16 & 96 \\
$100.001-500.000$ & 20,28 & 11,49 & 57 & 47 & 17 & 94 \\
$<500.001$ & 16,41 & 14,45 & 91 & 45 & 22 & 90 \\
\hline Total & 19,38 & 13,82 & 71 & 50 & 21 & 96 \\
\hline
\end{tabular}

IV (Indice de Vejez) ..................... Viejos por cada 100 jóvenes

ID (Indice de Dependencia) ............... Jóvenes y viejos por cada 100 adultos

IDV (Indice de Dependencia Viejos) ....... Viejos por cada 100 jóvenes

MASC. (Relación de masculinidad) ......... Hombres por cada 100 mujeres

Fuente: Elaboración propia a partir de INE, SAETAmunicipal, 1991. 
evidencian que la relación entre tamaño demográfico municipal y nivel de envejecimiento es claro, y solamente las ciudades de mayor tamaño rompen la tendencia general de la serie. Ello no quiere decir que haya homogeneidad de comportamientos, pues los índices de los municipios más rurales (menores de 500 habitantes) se disparan desde todas las perspectivas, poniendo en evidencia su bajísima proporción de jóvenes (menor de 10\%) y la elevada participación de mayores de 65 años (superior al 25\%).

El único indicador que presenta una correlación perfecta con el tamaño municipal es el índice de masculinidad. Esta relación -calculada para el total de población- aprecia, por encima de cualquier otro elemento, la influencia de las migraciones y su papel desigual según sexo, siendo el mundo urbano tradicional receptor de mujeres.

En aquellos indicadores específicos de la vejez (porcentaje de mayores de 65 años, índice de vejez e índice de dependencia de viejos) los indicadores aproximan los comportamientos de las ciudades medias y pequeñas; en cambio, aquellos en los que participa la población joven (proporción de jóvenes, índice de dependencia) acentúan las diferencias entre ellas, por lo que la serie rompe su tendencia en los municipios que superan los 100.000 habitantes.

A la vista de que uno de los rasgos estructurales más significativos actualmente es el envejecimiento demográfico, se ha puesto en relación este fenómeno y el tamaño demográfico municipal (figura 3 ). El resultado es que a pesar de la variabilidad de los casos considerados individualmente -manifiesta sobre todo en aquellos municipios de pequeño número de habitantes donde los porcentajes oscilan de forma drástica- la regla general marca una relación directa entre envejecimiento y tamaño demográfico. Así, la propensión hacia un porcentaje menor de ancianos a medida que se aumenta el tamaño demográfico municipal es continua hasta llegar a los 100.000 habitantes, momento en que la tendencia se estanca para acabar con un leve ascenso en el tramo final de la secuencia.

\section{A modo de conclusión}

La plena instauración de la informática en el mundo de la estadística ha supuesto una serie de rápidos cambios de los que el Censo

$$
-619-
$$




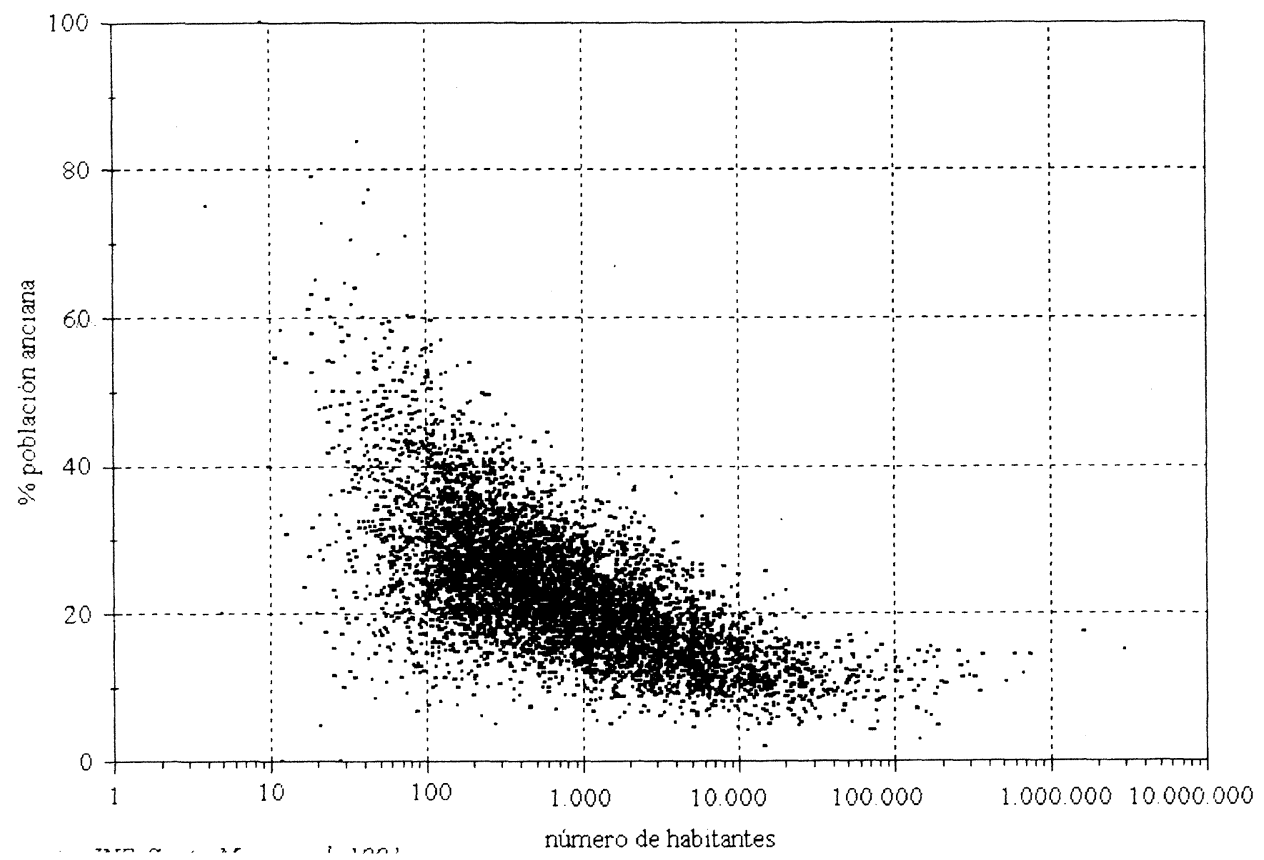

Fuente: INE, Saeta Muncipal, 1991.

FIGURA 3.-Envejecimiento según tamaño municipal, 1991

de 1991 es un claro exponente. La grabación de los datos de casi 40 millones de habitantes no es obstáculo para obtener tabulaciones referidas a los más de 8.000 municipios españoles. La substitución de las publicaciones en papel por otras en disquete, cinta o CD-Rom son la muestra física de estos cambios. Esta revolución de la información afecta ineludiblemente a las investigaciones, ya que, por primera vez, es posible disponer de un gran volumen de información a nivel municipal, hecho que incentiva la realización de trabajos a macroescala. A menudo, este tipo de estudios dificulta la identificación y comparación de procesos, máxime si se tiene en consideración la complejidad del mapa municipal español, tanto por su gran fragmentación como por la diversidad de formas de poblamiento existentes. En este contexto surge la necesidad de formular generalizaciones que sirvan como punto de referencia cuando se aborde el estudio de casos indi-

$$
-620-
$$


viduales. Así pues, cobra sentido el uso de escalas de análisis territorial intermedias, tales como las agregaciones según tamaño demográfico municipal.

Pese a las limitaciones que se han ido presentando, este criterio de clasificación ha permitido establecer trayectorias comunes en función del tamaño municipal, trayectorias en las que el éxodo rural se revela como un elemento determinante. El impacto de las migraciones no sólo ha condicionado la distribución actual de la población sino que también ha modelado las estructuras por edades, al igual que ha influido directamente sobre la dinámica natural. Por su parte, el Censo de 1991 muestra una serie de modificaciones en las relaciones entre población y tamaño municipal que alteran el esquema tradicional. Entre los cambios más significativos cabe señalar el estancamiento del crecimiento poblacional de las grandes ciudades que contrasta con el auge de las de tamaño medio, que son las que crecen de forma más rápida durante el último decenio. Los procesos de suburbanización y la relocalización de los focos de dinamismo económico suponen un desplazamiento de la capacidad de atracción desde las grandes urbes hacia las ciudades medias e incluso pequeñas. En cuanto a los municipios de menor tamaño, se aprecia una reducción notoria de sus flujos emigratorios en este período, lo que no impide que sigan siendo el conjunto que experimenta tasas de decrecimiento más acentuadas.

El análisis de las estructuras por edad pone en evidencia que el envejecimiento de la población española alcanza en 1991 proporciones hasta entonces nunca conocidas. Las grandes ciudades y los municipios más pequeños constituyen, paradójicamente, las categorías más envejecidas aunque como consecuencia de procesos muy distintos.

Sin duda, las pautas generales descritas son matizables mediante estudios de detalle que pongan a la luz la existencia de un amplio abanico de situaciones. No obstante, el análisis de casos concretos debería tomar como punto de partida escenarios más generales definidos en base a procesos geodemográficos comunes, como los que la aplicación de una óptica por tamaños municipales ha permitido trazar. 


\section{BIBLIOGRAFÍA}

Abellán, A. y Rodríguez, V. (1989): «Proceso de envejecimiento de la población española (1970-1981)». Análisis del desarrollo de la población española en el periodo 19701986. Madrid, Síntesis, pp. 357-364

Abellan, A., et al. (1996): Envejecer en España: manual estadístico sobre el envejecimiento de la población. Madrid, Fundación Caja de Madrid.

BielzA, V. (Coord.) (1989): Territorio y sociedad en España. Vol 2. Madrid, Taurus.

Camarero, L. A.(1993): Del éxodo rural y del éxodo urbano. Madrid, Ministerio de Agricultura, Pesca y Alimentación.

CAPel, H. (1975): «La definición de lo urbano». Estudios Geográficos, n. ${ }^{\text {os }} 138-139$, pp. 264-301

Ferrer, M., et al. (1988): «El sistema de población urbano y rural en España». Papeles de Economía Española, n. ${ }^{\circ}$ 34, pp. 209-239.

Ferrer, M. y Calvo, J. J. (1994): Declive demográfico, cambio urbano y crisis rural. Pamplona, Eunsa.

Higueras, A. y Faus, M. C. (1992): Rural depopulation. Zaragoza: Universidad de Zaragoza-Diputación General de Aragón.

LÓPEZ JiMÉnEZ, J. J. (1991): «Envejecimiento, tamaño demográfico y sector de actividad en los municipios españoles». Estudios Territoriales, n. ${ }^{\circ}$ 36, pp. 163-182.

Méndez, R. y CARAvaca, I. (1993): Procesos de reestructuración industrial en las aglomeraciones metropolitanas españolas. Madrid, Ministerio de Obras Públicas y Transportes.

Moreno Jiménez, A. (1987): «Concentración de la población y jerarquía de asentamien tos en España. Evolución y perspectivas». Estudios Territoriales, n. ${ }^{\circ}$ 24, pp. 77-108.

PRECEDo Ledo, A. (1986): «Las modificaciones del sistema urbano español en la transición postindustrial». Estudios Territoriales, n. ${ }^{\circ} 20$, pp. 121-138.

Reques, P. y Rodriguez Rodriguez, V. (1996): «Prospectivas demográficas y territoriales». Treballs de la Societat Catalana de Geografia. n. ${ }^{\circ}$ 41, pp. 173-222.

Rodriguez Osuna, J. (1983): «Proceso de urbanización y desarrollo económico en España». Ciudad y Territorio, n. ${ }^{\circ} 55$, pp. 25-42.

- (1985): Población y territorio en España. Siglos XIX-XX. Madrid, Espasa Calpe.

Sánchez Agullera, D. y García Coll, A. (1995): «Envejecimiento y ruralidad en España: perspectiva geodemográfica y consideraciones sociales». IV Congreso de la ADEH. Bilbao, ADEH-UPV.

Serrano Martínez, J. M. (1986): «Distribución espacial en España de las ciudades de tamaño intermedio (25.000-50.000 habitantes)». Estudios Territoriales, n. ${ }^{\circ}$ 20, pp. 139 160.

Toвfo, C. (1985): «Freno y redistribución del crecimiento demográfico en España. 197175 y 1976-81». Estudios Territoriales, n. ${ }^{\circ} 19$, pp. 57-67.

VÁzquez BARquero, A. (1986): «El cambio del modelo de desarrollo regional y los nuevos procesos de difusión en España». Estudios Territoriales, n. ${ }^{\circ}$ 20, pp. 87-110.

Vidal Bendito, T. (1989): «La población rural en España. Cambios estructurales 1960 1980». Análisis del desarrollo de la población española en el periodo 1970-1986. Madrid, Síntesis, pp. 37-55.

VInUESA, J. y VIDAL, M. ${ }^{\text {a }}$ J. (1991): Los procesos de urbanización. Madrid, Síntesis.

VINUESA, J. (1996): «Dinámica de la población urbana en España (1857-1991)». Ciudad y Territorio/Estudios Territoriales, n. ${ }^{\circ}$ 107-108, pp. 185-216.

NOTA: Agradecemos al grupo «Població i Territori» del Departament de Geografia Humana de la Universitat de Barcelona la cesión de la base municipal española. 
RESUMEN: Este trabajo presenta una actualización de los datos referentes a la población española agrupada en diversas categorías definidas a partir del tamaño demográfico municipal. Esta escala intermedia de análisis, que goza de una amplia tradición de trabajos, desaparece de la publicación de los resultados correspondientes al Censo de Población de 1991, donde se pasa de la escala provincial a la municipal sin ningún tipo de estadio intermedio.

A pesar de las limitaciones de este tipo de clasificación, la revisión del comportamiento de los municipios agrupados según tamaños ha permitido establecer trayectorias comunes en su historia demográfica en cuanto a crecimiento de la población, naturaleza y su estructura demográfica.

ABSTRACT: This paper is an update on the grouping of the Spanish population by municipal demographic size. This intermediate scale analysis, although traditionally important, is not included in the publications of the results from de 1991 Population Census. These results go from the provincial to the municipal scales, skipping any intermediate states.

Despite its limitations, this kind of classification has proved useful in the analysis of the behaviour of the municipalities. It has allowed to establish common paths in municipal demographic history (population growth, migration and their demographic structure).

Résumé: Ce travail présente une actualisation des donées vis à vis à la population espagnole regroupée en différentes catégories définies à partir de la taille démographique communale. Cette échelle intermédiaire d'analyse, qui jouit d'une longue tradition de travaux, a disparu de la publication des résultats correspondants au recensement de la Population de 1991, qui passe de l'échelle provinciale à la municipale sans aucun genre d'échelon intermédiare.

Malgré les limites de ce genre de classification, la révision de la tendance des communes regroupées selon la taille nous a permis d'etablir les trajectoires communes dans leur histoire démographique, en relation à la croissance de la population, la nature et la structure démographique. 